\title{
Round Nodule
}

National Cancer Institute

\section{Source}

National Cancer Institute. Round Nodule. NCI Thesaurus. Code C157674.

Nodule shape conforming to a roughly spherical shape, independent of spiculations. 